\title{
Release and antibacterial activity of allyl isothiocyanate $/ \beta$-cyclodextrin complex encapsulated in electrospun nanofibers
}

\author{
Zeynep Aytac ${ }^{\mathrm{a}, \mathrm{b}}$, Sema Y. Dogan ${ }^{\mathrm{c}}$, Turgay Tekinay ${ }^{\mathrm{c}, \mathrm{d}}$, Tamer Uyar ${ }^{\mathrm{a}, \mathrm{b}, *}$ \\ a Institute of Materials Science \& Nanotechnology, Bilkent University, Ankara 06800, Turkey \\ ${ }^{\mathrm{b}}$ UNAM-National Nanotechnology Research Center, Bilkent University, Ankara 06800, Turkey \\ c Gazi University, Life Sciences Application and Research Center, Ankara 06830, Turkey \\ d Gazi University, Polatl Science and Literature Faculty, Ankara 06900, Turkey
}

\section{A R T I C L E I N F O}

\section{Article history:}

Received 21 December 2013

Received in revised form 19 March 2014

Accepted 13 April 2014

Available online 22 May 2014

\section{Keywords:}

Electrospinning

Nanofibers

Allyl isothiocyanate

$\beta$-Cyclodextrin

Release

Antibacterial activity

\begin{abstract}
A B S T R A C T
Allyl isothiocyanate (AITC) is known as an efficient antibacterial agent but it has a very high volatility. Herein, AITC and AITC/ $\beta$-cyclodextrin (CD)-inclusion complex (IC) incorporated in polyvinyl alcohol (PVA) nanofibers were produced via electrospinning. SEM images elucidated that incorporation of AITC and AITC $/ \beta-C D-I C$ into polymer matrix did not affect the bead-free fiber morphology of PVA nanofibers. ${ }^{1} \mathrm{H}-\mathrm{NMR}$ and headspace GC-MS analyses revealed that very low amount of AITC was remained in PVA/AITC-NF because of the rapid evaporation of AITC during the electrospinning process. Nevertheless, much higher amount of AITC was preserved in the PVA/AITC/ $\beta$-CD-IC-NF due to the CD inclusion complexation. The sustained release of AITC from nanofibers was evaluated at $30^{\circ} \mathrm{C}, 50^{\circ} \mathrm{C}$ and $75^{\circ} \mathrm{C}$ via headspace GC-MS. When compared to PVA/AITC-NF, PVA/AITC/ $\beta-C D-I C-N F$ has shown higher antibacterial activity against Escherichia coli and Staphylococcus aureus due to the presence of higher amount of AITC in this sample which was preserved by CD-IC.
\end{abstract}

(C) 2014 Elsevier B.V. All rights reserved.

\section{Introduction}

Electrospinning is a widely used method to produce functional nanofibers from variety of materials including polymers, inorganic materials and composite structures [1,2]. Generally electrospinning is a room temperature process in which the polymer solution is exposed to electrostatic field and the electrified jet is drawn toward to the grounded collector and deposited on the collector as a fibrous web. As the solvent evaporates during the process, nanofibrous materials with unique properties having very high surface area to volume ratio and nanoporous structures are produced $[1,2]$. The unique properties enable electrospun nanofibers to be used in wound dressing, tissue scaffold, drug delivery, food packaging, filtration, energy, catalysis, sensors, etc. $[1,2]$. Owing to the room temperature and ambient process conditions that provide protection for the bioactive compounds in electrospun nanofibers,

\footnotetext{
* Corresponding author at: Institute of Materials Science \& Nanotechnology (UNAM), UNAM, Bilkent University, 06800 Ankara, Turkey. Tel.: +90 312290 3571; fax: +903122664365 .

E-mail addresses: tamer@unam.bilkent.edu.tr, tameruyar@gmail.com (T. Uyar).
}

electrospinning is used for production of functional nanofibers containing active agents like antioxidants [3,4], flavors/fragrances $[5,6]$ and antibacterial agents [7].

Active agents loaded electrospun nanofibers may be useful in food packaging [3,4,7-11] and biomedical applications [12-14] as reported in the literature. Vega-Lugo et al. made comparison in terms of release characteristics of free AITC and AITC $/ \beta-C D-I C$ including soy protein nanofibers with changing relative humidity and they also studied the effect of AITC amount on the release of AITC from AITC including polylactic acid nanofibers in different relative humidity [8]. In another related study, Ge et al. produced materials for food packaging applications by immobilizing glucose oxidase enzyme in polyvinyl alcohol/chitosan/tea extract electrospun nanofibrous membrane [9]. In a study conducted by our research group, polylactic acid nanofibers incorporated with inclusion complex of triclosan and cyclodextrins were produced via electrospinning [7]. In a study of Pérez-Masiá et al., a phase changing material was encapsulated in electrospun zein fibers for the possible application as smart packaging materials [10]. With regards to biomedical applications, Mattanavee et al. (2009) prepared different biomolecules immobilized electrospun polycaprolactone nanofibers with the purpose of using them in tissue 


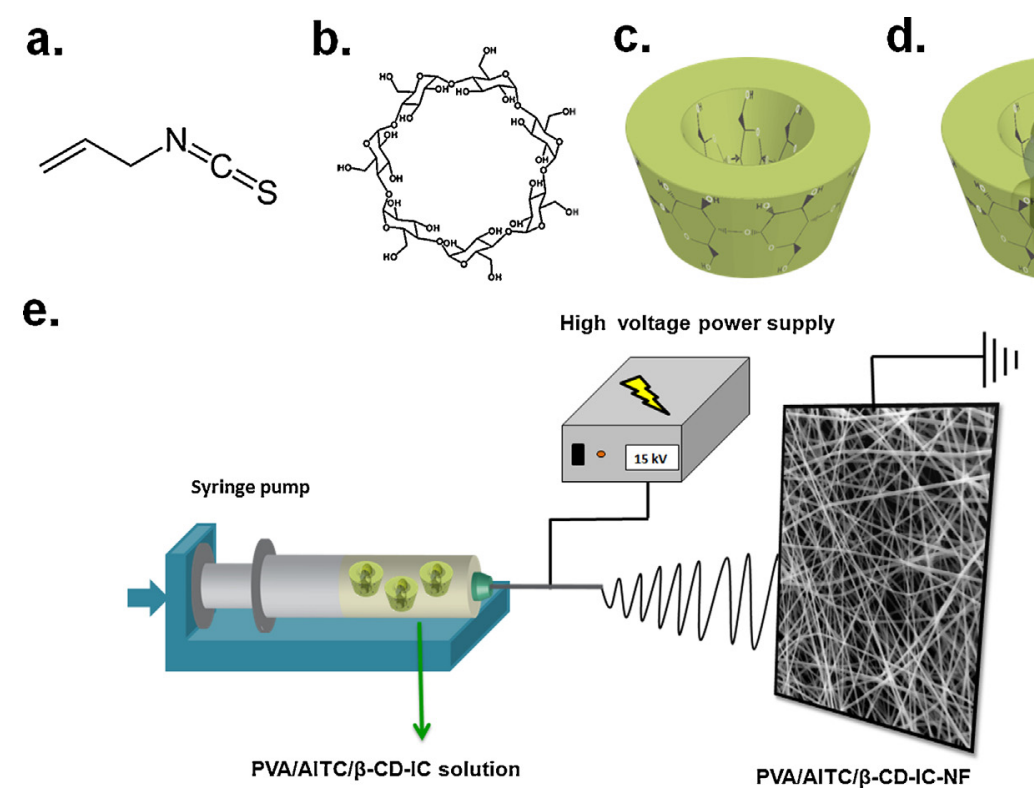

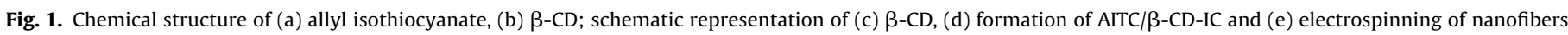
from PVA/AITC/ $\beta-C D-I C$ solution.

engineering [12]. Merrell et al. obtained curcumin-antioxidant agent-loaded electrospun polycaprolactone nanofibers for diabetic wound dressing applications [13]. In the study of Unnithan et al., an antibacterial electrospun nanofibers that are intended to be used as wound dressing material were produced by electrospinning of a drug - ciprofloxacin $\mathrm{HCl}$ - including solution of dextran and polyurethane [14].

Cyclodextrins (CD) are cyclic oligosaccharides (Fig. 1b) and able to form inclusion complex (IC) with variety of molecules. CD have $\alpha-(1-4)$ linkages forming a truncated-cone shaped structure (Fig. $1 \mathrm{c}$ ). $\alpha-\mathrm{CD}, \beta-\mathrm{CD}$ and $\gamma$-CD having $6,7,8$ glucopyranose units are the most common CD types [15,16]. Owing to their hydrophobic cavity, $\mathrm{CD}$ are able to form host-guest complexes via weak forces, such as van der Waals interactions, dipole-dipole interactions, and hydrogen bonding with molecules in appropriate polarity and dimension. IC of CD with a guest molecule has advantages like providing higher solubility, higher thermal stability and bioavailability of hydrophobic guests; controlling of volatility, masking off unpleasant odors, and controlling release of drugs and flavors [15-17]. CD are widely used in pharmaceutical, cosmetics, biotechnology, agriculture, textile, chemical, environmental protection industries [15-17]. There also exist studies concerning application of $\mathrm{CD}$ in active food packaging [18-20] and biomedical applications [21-23] in the literature. In the food packaging studies, CD were incorporated with polymers in free form to capture undesired molecules in the foods like cholesterol [18], hexanal and cholesterol [19] or in guest molecule-CD-IC form to release an antimicrobial agent (trans-2hexenal) [20]. IC of CD and various types of drugs are prepared and these CD-drug-IC could be used in biomedical applications [21-23].

Allyl isothiocyanate (AITC) (Fig. 1a) is a major pungent, an antimicrobial compound found in cabbage, horseradish, mustard, wasabia and used in food packaging [24], and biomedical applications $[25,26]$. IC of AITC with CD was investigated in the literature $[27,28]$. In a study of Li et al., release rate of IC of AITC and $\alpha-C D$ and IC of AITC and $\beta-C D$ was investigated against relative humidity [27]. In another study, Ohta et al. studied on the decomposition and thermodynamic properties of inclusion complexation of AITC and $\mathrm{CD}(\alpha-\mathrm{CD}$ and $\beta-\mathrm{CD})[28]$.
AITC could be used in food packaging applications by incorporating it into polymeric films [29] or fibers [8]. Plackett et al. investigated the effect of $C D$ type in the release behavior of AITC from AITC/CD-IC incorporated into polylactic acid-polycaprolactone films [29]. Vega-Lugo et al. studied the release of AITC from only AITC and AITC/ $\beta$-CD-IC including soy protein nanofibers at different relative humidity [8].

In this study, AITC encapsulated in electrospun polyvinyl alcohol (PVA) nanofibers were generated by two methods. PVA as a nanofiber matrix was chosen since PVA is a suitable polymer type for food packaging applications shown in the literature by incorporating different molecules or bacteria into PVA films [30] and fibers [5,31] due to its high tensile strength, flexibility, high oxygen and barrier properties. Free AITC and inclusion complex of AITC with $\beta$-CD (AITC $/ \beta-C D-I C)$ (Fig. 1d) prepared in aqueous solution was incorporated into PVA solution; then PVA/AITC and PVA/AITC/ $\beta$ CD-IC nanofibers were produced via electrospinning (Fig. 1e). The resulting nanofibrous webs were characterized by SEM, XRD, and ${ }^{1} \mathrm{H}$-NMR. The release of AITC from nanofibers was measured at $30^{\circ} \mathrm{C}, 50^{\circ} \mathrm{C}$ and $75^{\circ} \mathrm{C}$ by headspace GC-MS. The antibacterial activities of nanofibers were tested against Escherichia coli (E. coli) and Staphylococcus aureus (S. aureus) according to colony counting method.

\section{Materials and methods}

\subsection{Materials}

Polyvinyl alcohol (PVA, $M_{\mathrm{w}} \sim 85.000-146.000 \mathrm{~g} / \mathrm{mol}$, Sigma Aldrich, 87-89\% hydrolyzed), allyl isothiocyanate (AITC, 95\%, Sigma Aldrich), beta-cyclodextrin ( $\beta-C D$, Wacker Chemie AG, Germany), deuterated dimethylsulfoxide (DMSO-d6, deuteration degree min 99.8\% for NMR spectroscopy, Merck) were purchased and used as-received without any further purification. Distilled water was supplied from Millipore Milli-Q ultrapure water system.

\subsection{Preparation of solutions}

AITC containing PVA nanofibers were prepared by incorporating AITC into PVA solutions via two methods. In the first method, free 
Table 1

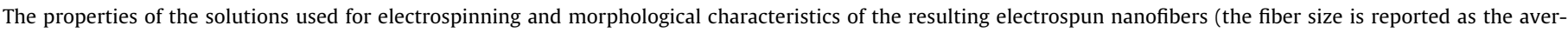
age \pm standard deviation and 100 fibers were analyzed for each case).

\begin{tabular}{|c|c|c|c|c|c|c|c|c|}
\hline Solutions & $\mathrm{PVA}^{\mathrm{a}}(\mathrm{g} / \mathrm{kg}, \mathrm{w} / \mathrm{v})$ & $\begin{array}{l}\beta-C D^{b} \\
(\mathrm{~g} / \mathrm{kg}, \mathrm{w} / \mathrm{w})\end{array}$ & $\begin{array}{l}\text { AITC }^{\mathrm{b}} \\
(\mathrm{g} / \mathrm{kg}, \mathrm{w} / \mathrm{w})\end{array}$ & $\begin{array}{l}\text { Viscosity } \\
\text { (Pa s) }\end{array}$ & $\begin{array}{l}\text { Conductivity } \\
(\mu \mathrm{S} / \mathrm{cm})\end{array}$ & $\begin{array}{l}\text { Average fiber } \\
\text { diameter }(\mathrm{nm})\end{array}$ & $\begin{array}{l}\text { Fiber diameter } \\
\text { range }(\mathrm{nm})\end{array}$ & Fiber morphology \\
\hline PVA & 75 & - & - & 0.177 & 470 & $290 \pm 65$ & $140-580$ & Bead-free nanofibers \\
\hline PVA/AITC & 75 & - & 40 & 0.267 & 487 & $210 \pm 45$ & $120-330$ & Bead-free nanofibers \\
\hline PVA/AITC/ $\beta$-CD-IC & 75 & 227 & 40 & 0.194 & 523 & $235 \pm 90$ & $90-540$ & Bead-free nanofibers \\
\hline
\end{tabular}

a With respect to solvent (water).

b With respect to polymer (PVA).

AITC (4\%, w/w, with respect to polymer) was dispersed in aqueous solution and then 7.5\% PVA (w/v) was put into this solution. The solution (PVA/AITC solution) was stirred at room temperature overnight and finally it was electrospun (PVA/AITC-NF). In the second method, $4 \%$ AITC ( $\mathrm{w} / \mathrm{w}$, with respect to polymer) was dispersed in aqueous solution, then $\beta-C D$ was added to give a molar ratio of $2: 1$ (AITC: $\beta-C D$ ) and resulting solution was stirred overnight at room temperature and white, turbid solution was obtained. Finally, 7.5\% PVA (w/v) was added (PVA/AITC/ $\beta-C D-I C$ solution), and PVA/AITC/ $\beta$-CD-IC solution was stirred $6 \mathrm{~h}$ more at room temperature and electrospun (PVA/AITC/ $\beta$-CD-IC-NF). For comparison, we have also electrospun PVA aqueous solution $(7.5 \%, \mathrm{w} / \mathrm{v})$ without AITC or AITC $\beta$-CD-IC. Table 1 summarizes the compositions of the solutions used for the electrospinning of the nanofibers.

\subsection{Electrospinning}

PVA, PVA/AITC and PVA/AITC/ $\beta$-CD-IC solutions were separately loaded into $3 \mathrm{~mL}$ plastic syringe (metallic needle with $0.8 \mathrm{~mm}$ inner diameter) and then electrospun by using the horizontal electrospinning setup. The solutions were pumped through a syringe pump (WPI, SP 101IZ) at $1 \mathrm{~mL} / \mathrm{h}$ rate. Cylindrical metal covered with aluminum foil was used as a collector. The electric field $(15 \mathrm{kV})$ was applied from a high voltage power supply (AU Series, Matsusada Precision Inc.) and the tip-to-collector distance was $10 \mathrm{~cm}$. Experiments were performed at $24-25^{\circ} \mathrm{C}$ under $17-20 \%$ humidity.

\subsection{Characterization and measurements}

The viscosity of PVA, PVA/AITC and PVA/AITC/ $\beta-C D-I C$ solutions were determined by Anton Paar Physica MCR 301 rheometer equipped with a cone/plate accessory (spindle type CP 40-2) at a constant shear rate of $100 \mathrm{~s}^{-1}$, at $25^{\circ} \mathrm{C}$ and the conductivity of solutions was measured by Inolab ${ }^{\circledR}$ Multi 720-WTW at room temperature.

The morphologies of the electrospun PVA-NF, PVA/AITC-NF and PVA/AITC/ $\beta$-CD-IC-NF were examined by scanning electron microscopy (SEM, FEI-Quanta 200 FEG). Prior to taking SEM images, nanofiber samples mounted on metal stubs with doublesided adhesive tape were coated with $5 \mathrm{~nm} \mathrm{Au} / \mathrm{Pd}$ (PECS-682) to minimize charging. Diameters of the nanofibers were measured directly from the SEM images $(n \geq 100)$ and average fiber diameter (AFD) was calculated.

The crystalline structure of PVA-NF, $\beta-\mathrm{CD}, \mathrm{PVA} / \mathrm{AITC}-\mathrm{NF}$ and PVA/AITC/ $\beta$-CD-IC-NF were recorded by X-ray diffraction (XRD, PANalytical X'Pert powder diffractometer) applying $\mathrm{Cu} K \alpha$ radiation in a $2 \theta$ range $7.5-30^{\circ}$.

The proton nuclear magnetic resonance $\left({ }^{1} \mathrm{H}-\mathrm{NMR}\right)$ spectra were recorded on Bruker DPX-400 in DMSO-d6 at $400 \mathrm{MHz}$ at $25^{\circ} \mathrm{C}$. $30 \mathrm{mg} / \mathrm{mL}$ of AITC, PVA-NF, $\beta-C D$, PVA/AITC-NF and PVA/AITC/ $\beta$ CD-IC-NF were dissolved in DMSO-d6 to examine the presence of AITC in the samples and stoichiometry of PVA/AITC/ $\beta-C D-I C-N F$. Integration of the chemical shifts $(\delta)$ given in parts per million (ppm) of the samples was calculated by using MestReNova software.
The cumulative amount of AITC released from PVA/AITCNF and PVA/AITC/ $\beta$-CD-IC-NF were determined for 240 min by headspace gas chromatography-mass spectrometry (GC-MS) of Agilent Technologies 7890A gas chromatograph coupled to an Agilent Technologies 5975C inert MSD with a triple-axis detector. The capillary column used was HP-5MS (Hewlett-Packard, Avondale, PA) $(30 \mathrm{~m} \times 0.25 \mathrm{~mm}$ i.d., $0.25 \mu \mathrm{m}$ film thickness $)$. The headspace GC-MS experiments were performed with a CTCPAL auto sampler. $20 \mathrm{mg}$ of PVA/AITC-NF and PVA/AITC/ $\beta$-CD-IC-NF taken from the aluminum foil were placed in $20 \mathrm{~mL}$ headspace glass vials. The vials were agitated at $500 \mathrm{rpm}$ at $30^{\circ} \mathrm{C}, 50^{\circ} \mathrm{C}$ and $75^{\circ} \mathrm{C}$ of incubation temperature and $20 \%$ relative humidity. Helium was used as carrier gas was at a flow rate of $1.2 \mathrm{~mL} / \mathrm{min}$. $500 \mu \mathrm{L}$ of vapor was injected to the headspace GC-MS by using a headspace injector (MSH 02-00B, volume: $2.5 \mathrm{~mL}$, scale: $60 \mathrm{~mm}$ ). The syringe temperature was $50^{\circ} \mathrm{C}$. Oven temperature was held at $50^{\circ} \mathrm{C}$ for $1 \mathrm{~min}$ and increased to $200^{\circ} \mathrm{C}$ at the rate of $20^{\circ} \mathrm{C} / \mathrm{min}$ and held at this temperature for $3 \mathrm{~min}$. Thermal desorption was conducted in the split mode (20:1). Headspace GC-MS analyses were carried out in the complete selected ion monitoring mode (SIM). Flavor 2 and NIST 0.5 libraries were used to decide AITC peak. The release experiment was performed in triplicate and the results were reported as average \pm standard deviation.

The antibacterial activity of PVA/AITC-NF and PVA/AITC/ $\beta$ CD-IC-NF was assessed by colony counting method against Gram-negative E. coli and Gram-positive S. aureus bacteria. $200 \mu \mathrm{L}$ of the $E$. coli and $S$. aureus grown overnight were inoculated into $10 \mathrm{~mL}$ of Luria-Bertani (LB) broth and nanofibers were sterilized by UV irradiation and put into the flasks. About $1 \mathrm{mg}$ of nanofiber samples and controls were incubated at $37^{\circ} \mathrm{C}$ and stirred $100 \mathrm{rpm}$ for $24 \mathrm{~h}$. Samples from each flask and controls were serially diluted, $100 \mu \mathrm{L}$ of each was spread onto LB agar and colonies were counted and photographed after $24 \mathrm{~h}$. All experiments were performed in triplicate and reported as average \pm standard deviation.

\section{Results and discussion}

\subsection{Morphology analysis of nanofibers}

As an aim toward producing PVA nanofibers (NF) encapsulating AITC, free AITC and inclusion complex of AITC with $\beta-C D$ (AITC/ $\beta-C D-I C$ ) was incorporated into PVA nanofibers (PVA/AITC$\mathrm{NF}$ and PVA/AITC/ $\beta-\mathrm{CD}-\mathrm{IC}-\mathrm{NF}$ ) by using electrospinning technique. The morphological characterization of PVA-NF, PVA/AITC-NF and PVA/AITC/ $\beta-C D-I C-N F$ was carried out via SEM. SEM images and average fiber diameter (AFD) along with fiber distributions of the nanofibers are depicted in Fig. 2. In the case of electrospinning of pristine PVA solution, bead-free and uniform PVA-NF having AFD of $290 \pm 65 \mathrm{~nm}$ was obtained. Then, we incorporated AITC and AITC/ $\beta$-CD-IC into PVA solution and then electrospinning was performed in order to obtain functional nanofibers. As clearly seen from SEM images, the incorporation of AITC or AITC $/ \beta-C D-I C$ did not cause any notable change in the morphology of the electrospun nanofibers. The AFD of PVA/AITC-NF and PVA/AITC/ $\beta$-CD-IC-NF was very close to each other which were $210 \pm 45 \mathrm{~nm}$ and $235 \pm 90 \mathrm{~nm}$, 

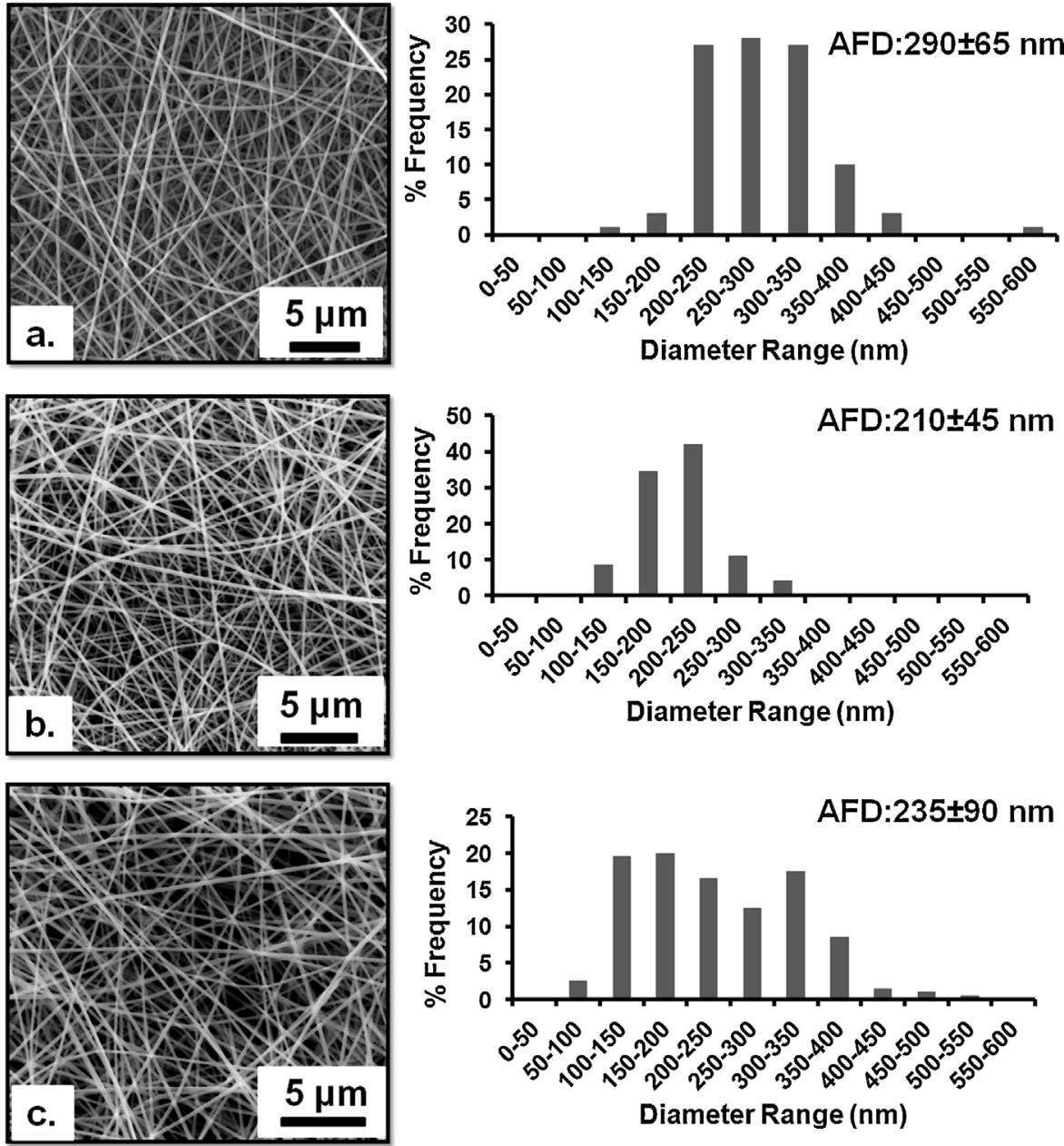

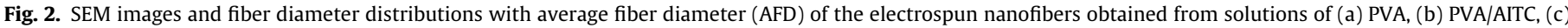
PVA/AITC/ $\beta-C D-I C$.

respectively. These nanofibers were slightly thinner than the PVANF. The slight variations of fiber diameters observed for the nanofiber samples were possibly due to differences in viscosity and conductivity of the solutions $[1,2,32]$. The viscosity, conductivity and AFD values of PVA, PVA/AITC and PVA/AITC/ $\beta$-CD-IC solutions are shown in Table 1. PVA/AITC and PVA/AITC/ $\beta$-CD-IC solutions have higher viscosity and higher conductivity compared to PVA solution.

\subsection{Crystalline structure of nanofibers}

XRD was performed for PVA-NF, $\beta-C D$, PVA/AITC-NF and PVA/AITC/ $\beta-C D-I C-N F$ and the diffraction patterns are depicted in Fig. 3. AITC is a liquid compound at room temperature, so we did not run XRD analysis for pure AITC. PVA is a semi-crystalline polymer and the XRD of PVA-NF has shown a broad diffraction at around $2 \theta \sim 19.6^{\circ}$ [33]. XRD pattern of PVA/AITC-NF was similar to PVA-NF, thus PVA keeps its semi-crystalline structure after incorporation of AITC. The cage-type packing crystal structure observed in CD generally transform into channel-type packing in CD-IC. The as-received $\beta-C D$ has a cage-type packing and its characteristic diffraction pattern is given in Fig. 3. The channel-type packing of $\beta-C D$ has salient characteristic peak at $2 \theta \sim 12^{\circ}[6]$. Here, the peak at $2 \theta \sim 12^{\circ}$ in XRD pattern of PVA/AITC/ $\beta$-CD-IC-NF was observed and we concluded that the IC formation between AITC and $\beta-C D$ in PVA/AITC $/ \beta-C D-I C-$ $\mathrm{NF}$ was present. In addition, the cage-type packing of $\beta-\mathrm{CD}$ pattern was absent in the fiber sample and this may support the AITC $/ \beta$ CD-IC formation as well.

\subsection{AITC content in nanofibers}

PVA/AITC-NF and PVA/AITC/ $\beta$-CD-IC-NF were tested by ${ }^{1} \mathrm{H}$ NMR to determine the stoichiometry of AITC/ $\beta-C D-I C$ and whether

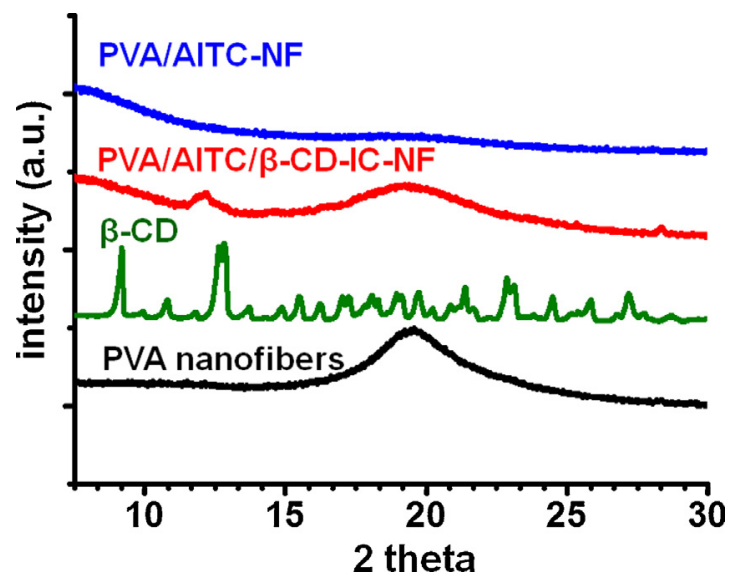

Fig. 3. XRD patterns of PVA nanofibers, $\beta-C D$ and AITC containing PVA nanofibers. 

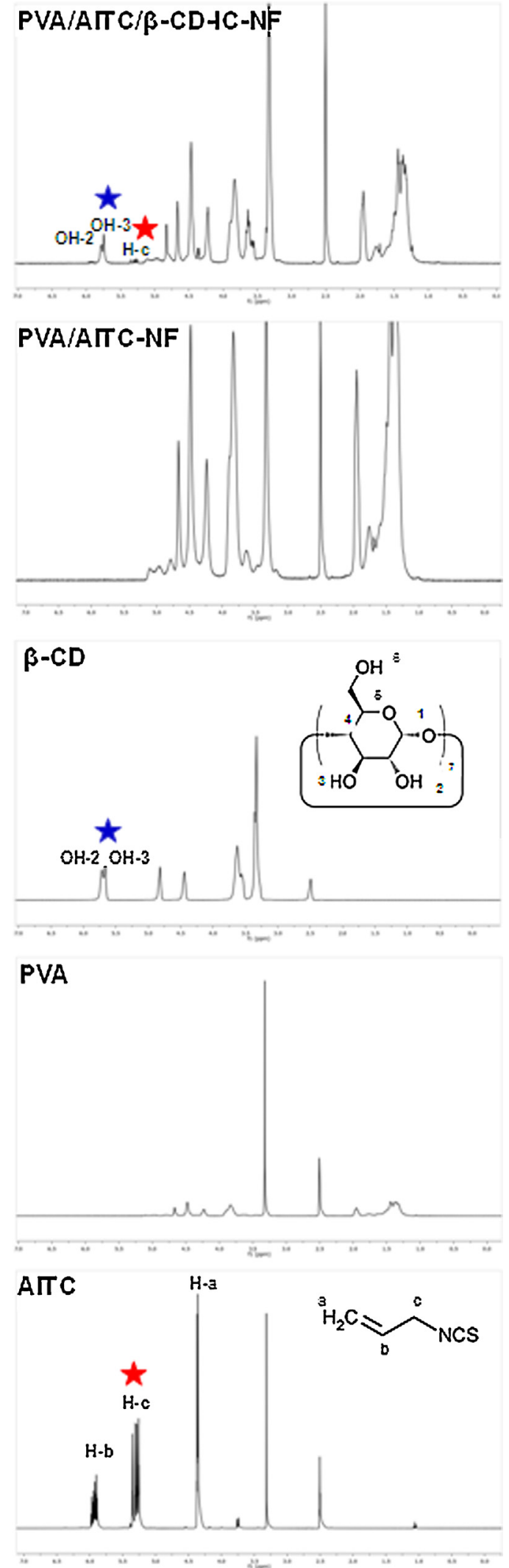

Fig. 4. ${ }^{1} \mathrm{H}-\mathrm{NMR}$ spectra of AITC, PVA, $\beta-\mathrm{CD}$ and AITC containing PVA nanofibers.

AITC was present in PVA/AITC-NF and PVA/AITC/ $\beta-C D-I C-N F$ (Fig. 4). The peaks for AITC were observed at around 4.2, 5.3, and $5.9 \mathrm{ppm}$ corresponding to the protons of AITC [34]. The stoichiometry of AITC and $\beta-C D-I C$ in PVA/AITC/ $\beta-C D-I C-N F$ was determined as $0.68: 1.00$ (AITC: $\beta$-CD) by integrating the peak ratio of the characteristic chemical shifts of AITC (5.3 ppm) and $\beta-C D(5.7 \mathrm{ppm})$. Thus, initial molar ratio of $2: 1$ for AITC: $\beta-C D$ which was used to obtain AITC $/ \beta$-CD-IC was preserved substantially. So, PVA/AITC/ $\beta$-CD-ICNF still contained some of AITC in the fiber sample whereas we could not observe any peak of AITC in PVA/AITC-NF. Therefore, we deduced that extremely low quantity of AITC exist in PVA/AITC-NF. The possible reason for this situation is evaporation of AITC during the electrospinning of solution since AITC is a highly volatile substance. In fact, we were able to smell AITC heavily during electrospinning of PVA/AITC-NF. In brief, ${ }^{1} \mathrm{H}-\mathrm{NMR}$ study showed that $\beta$-CD prevented evaporation of AITC to some extent during electrospinning process and high loading of AITC in PVA/AITC/ $\beta$-CD-IC-NF was achieved compared to PVA/AITC-NF.

\subsection{The release study of AITC from nanofibers}

The application of AITC is somehow restricted because of its highly volatile nature, unpleasant odor and hydrophobic nature [27]. Here, we have incorporated AITC/ $\beta$-CD-IC into PVA polymer solution, and PVA/AITC/ $\beta-C D-I C-N F$ were obtained via electrospinning. For a comparative study, we have also produced PVA/AITC-NF without CD-IC. There have been reports in the literature about the application of $\mathrm{CD}$ in food packaging materials to control the delivery of active compounds [8,20,27,29]. Here, we have evaluated the release behavior of AITC from PVA/AITC-NF and PVA/AITC $/ \beta$-CD-IC-NF at three different temperatures $\left(30^{\circ} \mathrm{C}, 50^{\circ} \mathrm{C}\right.$ and $75^{\circ} \mathrm{C}$ ) by using headspace GC-MS (Fig. 5).

The cumulative amount of AITC released at $30^{\circ} \mathrm{C}, 50^{\circ} \mathrm{C}$ and $75^{\circ} \mathrm{C}$ (for $240 \mathrm{~min}$ ) from PVA/AITC-NF were minimal and significantly much lower than that of PVA/AITC/ $\beta-C D-I C-N F$ sample. It is evident that very small amount of AITC was present in the PVA/AITC-NF sample as also confirmed by ${ }^{1} \mathrm{H}-\mathrm{NMR}$ studies which we could not even detect AITC in this sample. In the case of PVA/AITC/ $\beta-C D$ IC-NF, the amount of AITC was significant and the release of AITC from the nanofiber sample was increased gradually with time and finally became constant. Hence, we have successfully produced PVA/AITC/ $\beta$-CD-IC-NF with a sustained release behavior of AITC. In addition, as the temperature was increased from $30^{\circ} \mathrm{C}$ to $75^{\circ} \mathrm{C}$, the amount of AITC released was also increased obviously for both PVA/AITC-NF and PVA/AITC/ $\beta-C D-I C-N F$ samples. This is related with the higher diffusion coefficient of molecules at higher temperatures [35]. At higher temperatures, the motion of polymer chains increases, so the movement of active molecule through the amorphous parts of the polymer is favored [36]. Moreover, the increment in the release of AITC from PVA/AITC/ $\beta-C D-I C-N F$ was much clearer than PVA/AITC-NF. In short, headspace GC-MS results clearly confirmed that the evaporation of AITC was hindered by CDIC and much higher amount of AITC was encapsulated in the PVA nanofibers when AITC was complexed with $\beta-C D$.

\subsection{Antibacterial activity of nanofibers}

AITC, the major pungent compound in plants, has been reported to have strong antimicrobial activity in both liquid and vapor forms. Here, we have tested the antibacterial activity of PVA/AITC-NF and PVA/AITC/ $\beta$-CD-IC-NF by colony counting method against Gram negative E. coli and Gram positive $S$. aureus bacteria. Fig. 6a shows representative images of bacteria colonies treated by PVA/AITCNF and PVA/AITC/ $\beta-C D-I C-N F$; and Fig. $6 b$ shows the effect of PVA/AITC-NF and PVA/AITC/ $\beta$-CD-IC-NF on the growth inhibition rate of $E$. coli and S. aureus. The growth inhibition rate (\%) of bacteria was calculated by assuming that plates without nanofibers have $100 \%$ growth. PVA/AITC-NF and PVA/AITC/ $\beta-C D-I C-N F$ exhibited $31.98 \%$ and $94.41 \%$ antibacterial activity against $E$. coli whereas 
PVA/AITC-NF

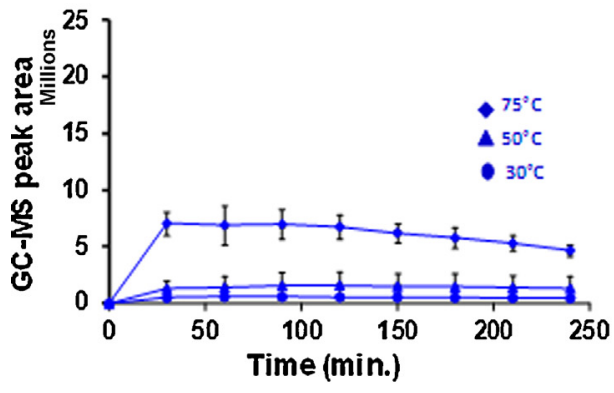

PVA/ATC/ $\beta-C D-I C-N F$

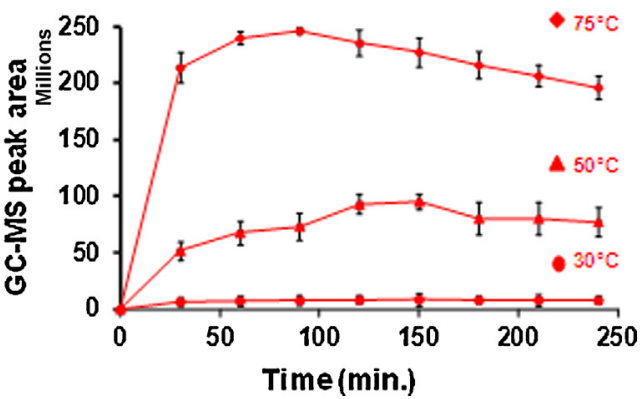

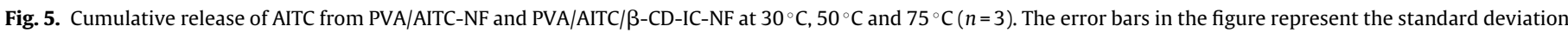
(SD).

antibacterial activity against S. aureus was 53.55\% and $99.82 \%$, respectively. It was obvious PVA/AITC/ $\beta$-CD-IC-NF sample (including about $0.0107 \mathrm{mg}$ AITC according to NMR result) has shown much better antibacterial activity when compared to PVA/AITC-NF. This is most likely due to the presence of higher amount of AITC in PVA/AITC/ $\beta-C D-I C-N F$ which was preserved by CD-IC. In the case of PVA/AITC-NF, some antibacterial activity against $E$. coli and $S$. aureus was observed since very low level of AITC was present in this sample as it was detected by headspace GC-MS analysis. Moreover, the electrospinning process in which very high voltages were applied has no negative effect on the antibacterial property of AITC encapsulated in PVA/AITC-NF and PVA/AITC/ $\beta$-CD-IC-NF. In addition, the difference in the antibacterial activity of both nanofiber samples against $E$. coli and $S$. aureus may be caused by the difference

a.
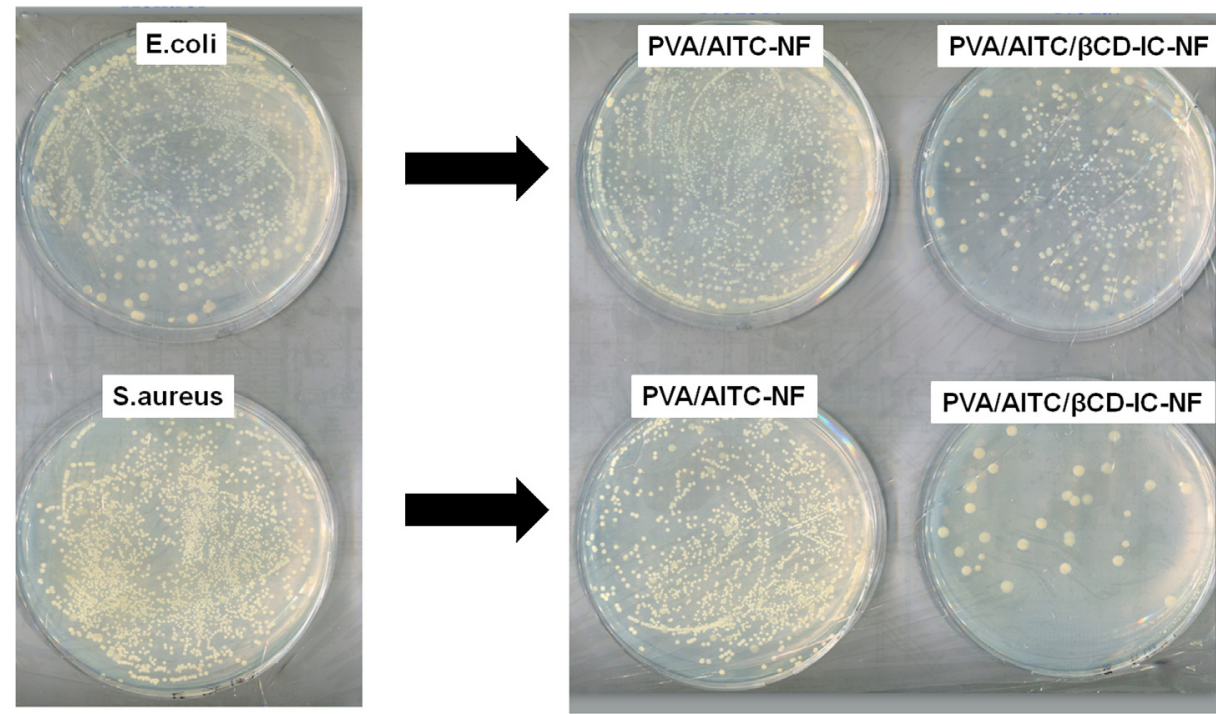

b.

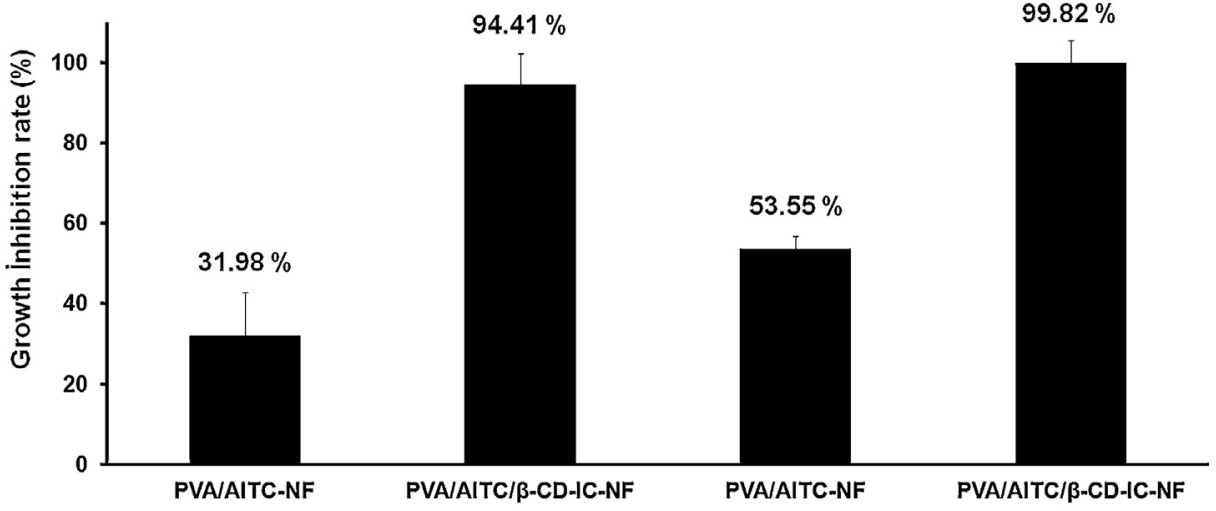

E.coli

S.aureus

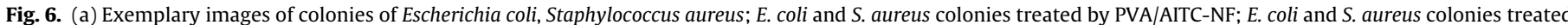

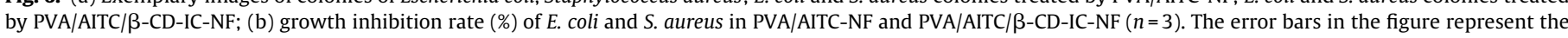
standard deviation (SD). 
between cell wall composition of two bacteria, which are Gram negative and Gram positive, respectively. Gram negative bacteria have a semi-permeable barrier that decelerates passing of compounds [37].

\section{Conclusion}

In this study, we performed the electrospinning of functional PVA nanofibers incorporating AITC and AITC/ $\beta$-CD-IC. SEM images showed that the bead-free fiber morphology of PVA nanofibers did not change after the incorporation of AITC and AITC/ $\beta-C D$-IC into polymer matrix. We observed that the extremely low quantity of AITC exist in PVA/AITC-NF due to the quick evaporation of AITC during the electrospinning of PVA/AITC solution since AITC has a highly volatile nature. On the contrary, much higher amount of AITC was encapsulated in the PVA/AITC/ $\beta$-CD-IC-NF sample due to the cyclodextrin inclusion complexation. Hence, PVA/AITC/ $\beta$ CD-IC-NF has shown improved antibacterial activity against $E$. coli and $S$. aureus when compared to PVA/AITC-NF without CD-IC. In brief, newly developed PVA/AITC/ $\beta-C D-I C-N F$ with high loading efficiency, sustained release behavior and considerably high antibacterial activity may have potentials for active food packaging and biomedical applications.

\section{Acknowledgments}

Dr. Uyar acknowledges The Scientific and Technological Research Council of Turkey (TUBITAK) (Project no. 111M459) and EU FP7-PEOPLE-2009-RG Marie Curie-IRG (NANOWEB, PIRG06-GA-2009-256428) and The Turkish Academy of Sciences-Outstanding Young Scientists Award Program (TUBAGEBIP) for funding the research. Z. Aytac thanks to TUBITAK (Project no.111M459) for the Ph.D. scholarship. Dr. Tekinay thanks Gazi University Scientific Research Project Unit for their support.

\section{References}

[1] S. Ramakrishna, An Introduction to Electrospinning and Nanofibers, World Scientific Publishing Company Incorporated, Singapore, 2005.

[2] J.H. Wendorff, S. Agarwal, A. Greiner, Electrospinning: Materials, Processing, and Applications, John Wiley \&Sons Publishing, Weinheim, 2012.
[3] A. Fernandez, S. Torres-Giner, J.M. Lagarón, Food Hydrocoll. 23 (2009) 1427.

[4] Y.P. Neo, S. Ray, J. Jin, M. Gizdavic-Nikolaidis, M.K. Nieuwoudt, D. Liu, S.Y. Quek, Food Chem. 136 (2012) 1013

[5] F. Kayaci, T. Uyar, Food Chem. 133 (2012) 641.

[6] T. Uyar, Y. Nur, J. Hacaloglu, F. Besenbacher, Nanotechnology 20 (2009) 125703

[7] F. Kayaci, O.C. Umu, T. Tekinay, T. Uyar, J. Agric. Food Chem. 61 (2013) 3901.

[8] A.-C. Vega-Lugo, L.-T. Lim, Food Res. Int. 42 (2009) 933.

[9] L. Ge, Y.-s. Zhao, T. Mo, J.-r. Li, P. Li, Food Control 26 (2012) 188.

[10] R. Pérez-Masiá, A. López-Rubio, J.M. Lagarón, Food Hydrocoll. 30 (2013) 182.

[11] C. Kriegel, A. Arrechi, K. Kit, D. McClements, J. Weiss, Crit. Rev. Food Sci. Nutr 48 (2008) 775

[12] W. Mattanavee, O. Suwantong, S. Puthong, T. Bunaprasert, V.P. Hoven, P. Supaphol, ACS Appl. Mater. Interfaces 1 (2009) 1076

[13] J.G. Merrell, S.W. McLaughlin, L. Tie, C.T. Laurencin, A.F. Chen, L.S. Nair, Clin. Exp. Pharmacol. Physiol. 36 (2009) 1149.

[14] A.R. Unnithan, N.A. Barakat, P. Tirupathi, G. Gnanasekaran, R. Nirmala, Y.-S. Cha, C.-H. Jung, M. El-Newehy, H.Y. Kim, Carbohydr. Polym. 90 (2012) 1786.

[15] E. Del Valle, Process Biochem. 39 (2004) 1033.

[16] J. Szejtli, Chem. Rev. 98 (1998) 1743.

[17] A.R. Hedges, Chem. Rev. 98 (1998) 2035.

[18] C. López-de-Dicastillo, M.a. Jordá, R.n. Catalá, R. Gavara, P. Hernandez-Munoz, J. Agric. Food Chem. 59 (2011) 11026.

[19] C. López-de-Dicastillo, M. Gallur, R. Catalá, R. Gavara, P. Hernandez-Munoz, J. Membr. Sci. 353 (2010) 184.

[20] M.J. Joo, C. Merkel, R. Auras, E. Almenar, Int. J. Food Microbiol. 153 (2012) 297.

[21] M.R. Freitas, L.A. Rolim, M.F.L.R. Soares, P.J. Rolim-Neto, M.M.d. Albuquerque, J.L. Soares-Sobrinho, Carbohydr. Polym. 89 (2012) 1095.

[22] S.K. Khalil, G.S. El-Feky, S.T. El-Banna, W.A. Khalil, Carbohydr. Polym. 90 (2012) 1244.

[23] M.D. Moya-Ortega, C. Alvarez-Lorenzo, H.k.H. Sigurdsson, A. Concheiro, T. Loftsson, Carbohydr. Polym. 80 (2010) 900.

[24] J. Shin, B. Harte, E. Ryser, S. Selke, J. Food Sci. 75 (2010) 65.

[25] S. Hayashi, E. Nakamura, T. Endo, Y. Kubo, K. Takeuchi, Inflammopharmacology 15 (2007) 218

[26] S. Hayashi, E. Nakamura, Y. Kubo, N. Takahashi, A. Yamaguchi, H. Matsui, S. Hagen, K. Takeuchi, J. Physiol. Pharmacol. 59 (2008) 691.

[27] X. Li, Z. Jin, J. Wang, Food Chem. 103 (2007) 461.

[28] Y. Ohta, K. Takatani, S. Kawakishi, Biosci. Biotechnol. Biochem. 64 (2000) 190.

[29] D. Plackett, A. Ghanbari Siahkali, L. Szente, J. Appl. Polym. Sci. 105 (2007) 2850

[30] B. Marcos, T. Aymerich, J.M. Monfort, M. Garriga, J. Food Sci. 75 (2010) 502.

[31] A. López-Rubio, E. Sanchez, Y. Sanz, J.M. Lagarón, Biomacromolecules 10 (2009) 2823.

[32] T. Uyar, F. Besenbacher, Polymer 49 (2008) 5336.

[33] J.H. Park, H.W. Lee, D.K. Chae, W. Oh, J.D. Yun, Y. Deng, J.H. Yeum, Colloid Polym. Sci. 287 (2009) 943.

[34] Y. Ohta, Y. Matsui, T. Osawa, S. Kawakishi, Biosci. Biotechnol. Biochem. 68 (2004) 671

[35] C.Y. Hu, M. Chen, Z.W. Wang, Packag. Technol. Sci. 25 (2012) 97.

[36] M. Galotto, A. Torres, A. Guarda, N. Moraga, J. Romero, Food Res. Int. 44 (2011) 566.

[37] M. Ignatova, Z. Petkova, N. Manolova, N. Markova, I. Rashkov, Macromol. Biosci. 12 (2012) 104 